\title{
Da Sindicalização às Ocupações: luta pela terra em Minas Gerais (1940-1980)
}

\author{
From Unionization to Occupation: the struggle for land in \\ Minas Gerais (1940-1980) \\ http://dx.doi.org/10.5007/2178-4582.2013v47n2p306
}

Arnaldo José Zangelmi

Universidade do Estado de Minas Gerais, Leopoldina/MG, Brasil

Fabrício Roberto Costa Oliveira

Universidade Federal de Viçosa, Viçosa/MG, Brasil

Izabella Fátima Oliveira de Sales

Centro Federal de Educação Tecnológica de Minas Gerais, Leopoldina/MG, Brasil

\begin{abstract}
O objetivo desse artigo é refletir sobre parte do processo de luta pela terra em Minas Gerais, principalmente no que se refere à segunda metade do século XX, buscando analisar algumas das principais mobilizações, atores e desdobramentos. Assim, buscamos conhecer os movimentos sindicais, a atuação de setores progressistas da Igreja Católica e a introdução das ocupações de terra enquanto estratégias legítimas de interlocução com o poder público. Realizamos uma análise da bibliografia sobre o assunto, depoimentos orais com alguns dos principais atores que participaram das mobilizações e matérias do Jornal Sem Terra. Para a realização desta pesquisa, nos valemos de alguns dos princípios metodológicos da história oral e da micro-história. Assim, pudemos observar tanto a conformação - entre os vários atores envolvidos de um quadro de descompassos, tensões e disputas pelo direcionamento das ações, quanto relações de convergência e continuidade em algumas experiências de luta ao longo do tempo.
\end{abstract}

Palavras-chave: luta pela terra; Minas Gerais; movimentos sociais.
The aim of this paper is to discuss the process of the struggle for land in Minas Gerais (Brazil), mainly with regard to the second half of the twentieth century, trying to analyze some of the major campaigns, actors and developments. Therefore, we sought to know the union movement, the work of progressive sectors of the Catholic Church and the introduction of land occupations as legitimate strategies for dialogue with the government. Given these goals, we conducted an analysis of the literature on the subject, of oral testimony of certain key actors who participated of the workers $\square$ movement and of the publications of the Jornal Sem-Terra. To carry out this research, we have used some methodological principles of oral history and micro-history. Thus, we could observe both the conformation of a framework of dissonances, tensions and disputes by directing actions, as the relations of convergence and continuity in some struggle experiences over time.

Keywords: struggle for land; Minas Gerais, social movements.

\section{Introdução}

Alguns estudos têm demonstrado como, em várias regiões do Brasil, as ocupações de terra redimensionaram as formas típicas de mobilização e se tornaram pontos centrais no estabelecimento de espaços de interlocução entre trabalhadores rurais, militantes de movimentos sociais e poder público (SIGAUD, 2000; ROSA, 2009; ONDETTI; WAMBERGUE; AFONSO, 2010). 
No entanto, o processo de luta pela terra em Minas Gerais ainda é pouco conhecido, sendo nebulosa a constituição histórica dessas novas formas de mobilização, o que dificulta a compreensão sobre seu contexto de emergência e significado político nesse estado. Assim, não tem ficado evidente como essas ações se tornaram viáveis, em grande medida, diante de um longo processo de lutas nas quais vários atores tiveram papel fundamental, desenvolvendo formas de mobilização que deram base para a inserção de novos atores e estratégias no final da década de 1970 e durante a década de 1980.

Diante dessa questão, o presente artigo é um esforço para trazer alguns elementos que contribuam para o esclarecimento desse processo, discutindo desde o processo inicial de sindicalização de trabalhadores rurais no estado e as estratégias iniciais de mobilização, passando pela forte atuação de setores progressistas da Igreja Católica na conscientização e organização de trabalhadores rurais, até a constituição inicial das ocupações de terra enquanto mecanismos legítimos de pressão sobre o poder público ${ }^{1}$.

Para tanto, nos valemos da bibliografia sobre o assunto, alguns depoimentos orais realizados junto a atores que participaram da mobilização de trabalhadores rurais em Minas Gerais e matérias do Jornal Sem Terra nas quais essas mobilizações foram retratadas. Para a realização desta pesquisa, nos valemos de alguns dos princípios metodológicos da história oral e da micro -história, buscando relacionar alguns contornos de trajetórias individuais com seus contextos de relações e inserções nos processos políticos mais amplos.

Assim, esperamos que essas discussões possam ajudar a colocar em questão a história da luta pela terra em Minas Gerais, incentivando a realização de futuras pesquisas que aprofundem as análises aqui colocadas.

\section{Apontamentos sobre a luta pela terra em Minas Gerais}

Diante do processo de intensificação das relações capitalistas no meio rural, marcado pela expropriação da terra dos trabalhadores rurais e pelo assalariamento, emergiram em meados do século XX, em Minas Gerais, várias formas de luta pela terra, desenvolvidas por uma variedade de atores, muitas vezes com sentidos distintos (MARTINS, 1981).

A partir das décadas de 1940 e 1950 acentuam-se os conflitos de posseiros, meeiros e arrendatários contra grandes proprietários que buscavam expulsá -los. Martins (1981) afirma que as lutas no leste mineiro remontam à década de 1940, quando posseiros advindos do Nordeste, que se estabeleceram na região, passaram a ser convertidos em parceiros, e, em seguida, expulsos por fazendeiros grileiros ao longo das décadas de 1940 e 1950. Como narra Pereira ${ }^{2}$ :

${ }^{1}$ Parte significativa das informações e reflexões disponibilizadas nesse artigo são resultado da pesquisa de doutorado realizada no Programa de Pós-Graduação de Ciências Sociais em Desenvolvimento, Agricultura e Sociedade, da Universidade Federal Rural do Rio de Janeiro, sob orientação da professora Leonilde Servolo Medeiros.

${ }^{2}$ Nas Terras do Rio Sem Dono (1980) é uma obra literária que retrata parte significativa dos conflitos pela terra no Vale do Rio Doce nas décadas de 1940 a 1960, fornecendo informações importantes para nossa contextualização sobre esse período. 
Tangido pela seca inclemente e fugido do latifúndio onde até a água tem dono, o lavrador nordestino vira $\square$ pau de arara. Emigra. Ajunta o que tem, vende o que pode, embarca num caminhão com a mulher e os filhos, Rio-Bahia abaixo. Descobre as terras do rio sem dono. Escolhe a sua $\square$ pela primeira vez a sua terra. Explode libertado trabalhando e produzindo, povoando e colonizando. Adoece e sofre, muitas vezes perde entes queridos no ermo da mata virgem. Rega a gleba com o seu suor . Mas, trabalha o que é seu. É o mais feliz dos homens. Um dia surge o grileiro astuto, desumano e implacável. É a luta pela terra que começa. Violenta, cruel e desigual (PEREIRA, 1980, p. 16-17).

Esses antigos posseiros passaram a se organizar em sindicatos e a resistir a esse processo de expropriação. Segundo Martins (1981), desde a década de 50 , os sindicatos dos trabalhadores rurais existem no Nordeste de Minas, mais especificamente na região de Governador Valadares, mesmo que ainda sem reconhecimento legal. Essas organizações $\square$ nesse quadro de violentos despejos realizados por fazendeiros nas décadas de 1940 e $1950 \square$ atraem rapidamente centenas de camponeses, o que acirrou ainda mais as tensões e conflitos com fazendeiros da região (Martins, 1981). Pereira afirma que:

É isto (grilagem e despejos) que explica o porque da intensidade arrebatadora que tomou a luta pela reforma agrária no Rio Doce. Jamais a arte ou o engenho de alguém $\square$ como querem fazer crer alguns $\square$ poderia ter forjado aquela avalanche que impressionou o Brasil às vésperas do Golpe de Abril. Já em $1955 \square$ em pleno auge dos despejos gigantescos de posseiros que marcaram as décadas de 40 e $50 \square$ realizou-se em Governador Valadares uma manifestação que podemos considerar das pioneiras na luta pela reforma agrária que depois sacudiu o país (PEREIRA, 1980, p. 78).

Segundo Camisasca (2009), as primeiras formas de organização dos trabalhadores rurais mineiros surgiram na década de 1940, em forma de ligas, porém com caráter bastante efêmero:

Contudo, foi possível notar que o trabalho de organização dos homens do campo em Minas não se iniciou na década de 1950, mas sim em meados dos anos 1940, com a formação das primeiras ligas camponesas, lideradas pelo PCB. Esses movimentos foram criados em algumas regiões do estado após a conquista da legalidade do partido em 1945. Em todo o estado foram criadas cerca de 7 ligas, entretanto, essas tiveram duração efêmera, pois, em 1947, o partido teve o seu registro cassado e essas organizações foram proibidas de funcionar (CAMISASCA, 2009, p.52).

A partir dos anos de 1950 foram criadas associações de lavradores em Minas Gerais, que tinham maior durabilidade e contribuíram para o amadu- 
recimento de práticas organizativas, apesar das dificuldades em se constituir formas de enfrentamento coletivo nesses grupos:

As organizações camponesas existentes no estado, nesse período, recebiam a denominação de associações de lavradores e trabalhadores agrícolas. Eram entidades de caráter civil, que para serem criadas necessitavam apenas da aprovação de um estatuto e do seu registro em cartório. Não existiam, assim, obstáculos legais que dificultassem a sua fundação (CAMISASCA, 2009, p. 51).

Devido à fraqueza do movimento, essas associações não conseguiram se opor, de forma coesa e consistente, ao poder dos proprietários de terras (CAMISASCA, 2009, p.52).

João do Mucuri ${ }^{3}$, um dos fundadores do sindicato de Poté (Vale do Mucuri) - primeiro Sindicato de Trabalhadores Rurais (STR) legalizado em Minas Gerais (08/07/1962) - narrou parte desse processo no que se refere ao Nordeste Mineiro, enfatizando como o Sindicato de Poté foi criado em face de um quadro crescente de expulsão, exploração e desamparo dos trabalhadores rurais da região.

Segundo João, na década de 1950, com a intensificação da expansão da agricultura em várias partes do Brasil, muitos agregados do Vale do Mucuri passaram a buscar trabalho em outras regiões. Com a saída desses trabalhadores, muitas mulheres e crianças ficavam economicamente desamparadas, muitas vezes sendo expulsas da terra pelos proprietários. Nesse processo, muitas famílias, mesmo com a presença dos homens, eram também expulsas pelos proprietários maiores, em vista da expansão da pecuária.

Diante desse quadro, um padre alemão chamado Paulo Teodoro passou a organizar um grupo de jovens em Poté, ligando-os à Juventude Agrária Católica (JAC) do Rio de Janeiro. A JAC é um dos setores da Ação Católica (AC) voltados para a mobilização política da juventude católica, em específico no meio rural (CAMISASCA, 2009). Segundo o sindicalista:

Ele (Padre Paulo Teodoro) iniciou com um grupo de jovens. No Rio de Janeiro, a nível nacional, organizou-se um grupo de jovens da Ação Católica, a Juventude Agrária Católica. Em Teófilo Otoni tinha a Juventude Estudantil Católica, a JEC. (...) E lá em Poté o padre convidou um grupo de jovens para organizar a JAC. E nós participamos desse grupo (João do Mucuri, entrevistado em 16 mar. 2011 pelos autores).

${ }^{3}$ João do Mucuri é sindicalista, fundador do STR de Poté e atualmente diretor da Federação dos Trabalhadores na Agricultura do Estado de Minas Gerais (FETAEMG) no polo de Teófilo Otoni. Todos os nomes dos entrevistados, em comum acordo com os mesmos, foram substituídos por pseudônimos, visando proteger os depoentes de possíveis constrangimentos. 
Nessa época, o Padre Teodoro trazia regularmente um jornal da JAC para esses jovens - O campo feito pelo Homem do campo - que era um veículo de trocas de experiências entre trabalhadores rurais organizados em várias regiões.

Inicialmente, esse grupo de Poté teve o objetivo de manter os trabalhadores rurais no campo, contribuindo para sua organização econômica, formando uma cooperativa de crédito $\square$ emprestando dinheiro para os trabalhadores rurais se estruturarem $\square$ e uma cooperativa agrícola, que ajudava na compra, venda e armazenamento dos produtos. Essas iniciativas geraram grande insatisfação dos comerciantes da região, que, segundo João, passaram a ter menor poder para explorar os trabalhadores rurais. Diante dessa tensão crescente, e incentivado por Padre Teodoro, esse grupo criou o sindicato para organizar os trabalhadores politicamente. Formado por pequenos produtores rurais e com apoio da Diocese de Teófilo Otoni esses jovens criaram, em 1962, o STR de Poté, e viajaram pela região incentivando a formação de sindicatos. Essas ações contribuíram para a futura criação da Federação dos Trabalhadores na Agricultura do Estado de Minas Gerais (FETAEMG).

Nessa época, também por iniciativa do Padre Teodoro, várias comunidades rurais da região passaram a ter acesso às transmissões radiofônicas dos cursos do Movimento de Educação de Base (MEB)4. Como afirma João do Mucuri:

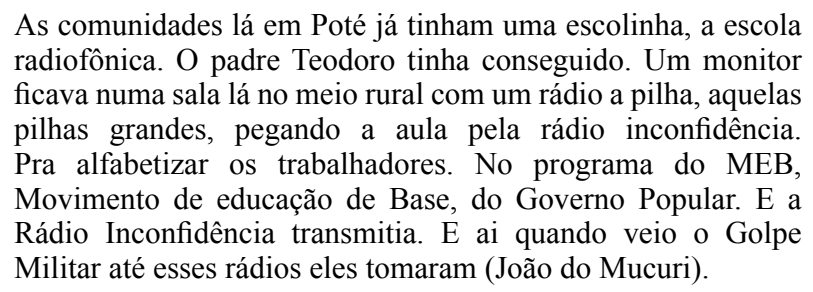

Ferreira Neto (1999), descrevendo e analisando parte da história do Movimento Sindical de Trabalhadores Rurais (MSTR) em Minas Gerais, discute como a sindicalização ocorreu pela ação de (e relação entre) vários grupos, como o Partido Comunista (PCB), Ação Popular (AP), Ligas Camponesas, partidos, poder público, etc..

Esse autor demonstra como o poder público, em consonância com os anseios do patronato rural e setores conservadores da Igreja Católica, incentivou a sindicalização como mecanismo de evitar o avanço de setores de esquerda - principalmente das Ligas Camponesas e o PCB $\square$ na organização e mobilização dos trabalhadores rurais pela reforma agrária. Como afirma, a interpretação conservadora era de que:

${ }^{4}$ O Movimento de Educação de Base (MEB) - fundado em 1961 pela Conferência Nacional dos Bispos do Brasil (CNBB) e financiado pelo governo federal - teve os objetivos de alfabetizar e conscientizar politicamente, principalmente através de escolas radiofônicas implantadas em várias regiões do Brasil, com base no método desenvolvido por Paulo Freire. Em Minas Gerais, a maior parte de seus integrantes eram membros da Ação Popular (AP), atuando também no processo de sindicalização rural (CAMISASCA, 2009). 
[....] a ausência de uma estrutura hierarquizada e institucionalizada, voltada para a representação dos trabalhadores rurais, deixava espaço aberto para que essa organização ocorresse à revelia dos mecanismos legais de controle, o que, naquela conjuntura, significava a possibilidade de consolidação de grupos, organizações e partidos políticos de esquerda (FERREIRA NETO, 1999, p. 165).

Assim, a legislação trabalhista foi a base para a atuação do próprio PCB na organização dos trabalhadores rurais, e para a forma como delimitou seu público e conduziu o processo de sindicalização, com forte viés de enquadramento ao espaço de atuação delimitado pelo Estado. Dessa forma, as ações no sentido de sindicalizar prevaleceram nesse período, ficando a luta pela reforma agrária em segundo plano, como uma busca mais articulada no âmbito institucional e formal.

Apesar do controle, esse processo foi importante para a criação de espaços institucionais de representação dos trabalhadores em Minas Gerais, mecanismo para organização e defesa de seus interesses que, de acordo com Ferreira Neto (1999, p. 173) foi gradualmente se ampliando, o que, em certa medida, contribuiu para criação de meios para pressão popular sobre o governo. Apesar dessa atuação supostamente se dar principalmente pelos caminhos delineados pelo Estado, desenvolviam-se também ações por outros caminhos, como demonstra este autor:

\begin{abstract}
No outro polo, preservados os momentos de sintonia com o PCB, situava-se a concepção de organização autônoma e de luta popular desenvolvida pelas Ligas Camponesas que apostavam na possibilidade de organização dos trabalhadores e da conquista de direitos e do próprio acesso à terra, à revelia dos favores e concessões do poder público (Ibid., p. 192).
\end{abstract}

Não somente grupos de esquerda $\square$ como PCB, Ligas Camponesas, setores progressistas da Igreja Católica, etc. $\square$ foram responsáveis pelo processo de sindicalização. Setores conservadores da Igreja Católica, principalmente representados pelos Círculos Operários Cristãos ${ }^{5}$, também buscaram disputar a sindicalização rural em Minas Gerais, visando, em certa medida, combater o avanço do socialismo no campo. Para Ferreira Neto:

[...] a polarização entre diferentes concepções ideológicas, no início do processo de constituição do movimento sindical dos trabalhadores rurais em Minas Gerais, vai acentuar o caráter regionalizado da implementação dos sindicatos em todo estado (FERREIRA NETO, 1999, p. 187).

\footnotetext{
${ }^{5}$ Os Círculos Operários Cristãos (COC), formados por segmentos conservadores da Igreja Católica, visavam inicialmente estreitar os laços dos trabalhadores com a doutrina católica. Esse grupo, em vários estados do Brasil, disputou o controle sobre os processos de sindicalização, visando principalmente conter o avanço de setores de esquerda.
} 
No início dos anos de 1960, os sindicatos dos Vales do Jequitinhonha, Mucuri e Rio Doce, formados principalmente por meeiros, posseiros e assalariados, estavam em sua maioria ligados ao PCB. Os sindicatos da Região Metropolitana de Belo Horizonte, Zona da Mata e Campos das Vertentes, formados por pequenos proprietários, estavam sob influência dos Círculos Operários (Ibid., p. 188). Grupos progressistas ligados à Igreja Católica, como a AP (Ação Popular), também tiveram grande relevância no processo de sindicalização em Minas Gerais \sobretudo no Triângulo, Vale do Rio Doce e sul de Minas (Ibid., p. 200), como percebemos também nos relatos de João do Mucuri.

De 1961 à 1964 o processo de sindicalização e a bandeira pela reforma agrária ganharam força no Brasil, principalmente a partir dos debates no Congresso Camponês de Belo Horizonte. Nesse período, a busca pela conquista de terras cresce consideravelmente em Minas Gerais. Na região de Governador Valadares, região com forte atuação do PCB, lideranças como Francisco Raimundo da Paixão (Chicão) e Carlos Olavo da Cunha Pereira atuaram fortemente na organização sindical e na busca pela conquista da terra. Nessa cidade, acumulavam-se trabalhadores rurais expulsos por grileiros, num clima de insatisfação crescente (CAMISASCA, 2009).

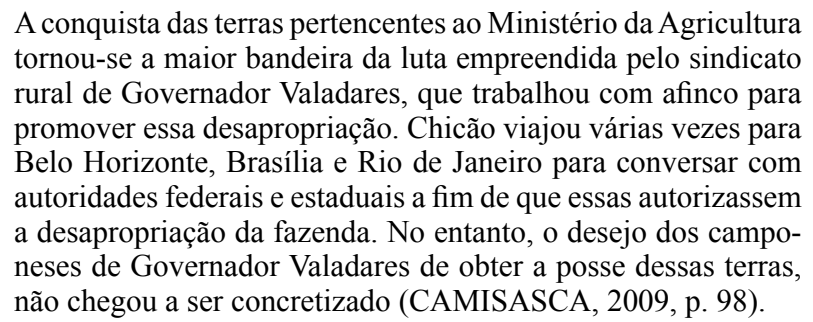

Analisando esse processo, Borges (2004) discute os conflitos entre fazendeiros e trabalhadores rurais, em especial os conflitos cercados pela atmosfera dos antecedentes do golpe militar de 1964. Segundo esta autora, na cidade de Governador Valadares, meeiros, parceiros, assalariados e moradores de favelas, unidos em sindicatos de trabalhadores rurais $\square$ motivados inicialmente pela atuação da Ação Popular e do Partido Comunista $\square$ antagonizaram com os fazendeiros locais, membros de igrejas e partidos conservadores, representantes do poder público local, etc.. De acordo com Borges (Ibid.), essa situação foi resultado do crescimento da tensão entre trabalhadores rurais e grileiros e da organização e mobilização dos setores subalternos no campo, na segunda metade da década de 1950 e início da década de 1960. E, como afirma Camisasca:

Em meados de 1963, sob a liderança de Chicão foi fundado o Sindicato dos Trabalhadores na Lavoura de Governador Valadares. Devido ao fato de Chicão não trabalhar no meio rural ele 
foi alvo de muitas críticas empreendidas pelos proprietários de terra e também pela imprensa, que asseguravam que o sapateiro somente queria promover agitação na cidade. (...) No início do ano de 1964 o sindicato já contava com a participação de cerca de 2.000 membros (CAMISASCA, 2009, p. 155- 156).

Em 1963 crescia a luta sindical pela reforma agrária, trazendo a ideia de tomar a Fazenda do Ministério ${ }^{6}$. Por outro lado, grandes proprietários rurais, em vista dos contextos local e nacional desfavoráveis, passaram a se organizar politicamente, a fazer comícios no Leste, Nordeste e Sul de Minas Gerais, com a presença de líderes religiosos e políticos (BORGES, 2004). A ocupação da fazenda do Ministério da Agricultura acirrou ainda mais os ânimos:

\begin{abstract}
No final do ano de 1963, apesar da desapropriação da fazenda do Ministério da Agricultura não ter sido decretada, cerca de 30 famílias de camponeses passaram a ocupar pacificamente a fazenda e aguardavam o recebimento do título de propriedade a ser emitido pelo governo federal. Devido a essa ocupação, o líder ruralista Josaphat Macedo afirmou que a fazenda federal havia se tornado o quartel general dos comunistas e um foco permanente de agitadores (...) Diante desse fato, a tensão entre as partes parecia se agravar, afinal o número de sindicalizados crescia assustadoramente e os camponeses percebiam que apenas a desapropriação da fazenda do Ministério da Agricultura não seria suficiente para abrigar a todos. Eles começaram então a se mobilizar para que outras terras também fossem desapropriadas (CAMISASCA, 2009, p. 157-158)
\end{abstract}

Essa tensão chamou atenção do poder público, que passou a enviar comissões para atuar na região, tentando estabelecer espaços de negociação entre os grupos, o que desagradou os fazendeiros que esperavam uma atuação mais favorável aos seus interesses, passando a organizar grupos armados para caçar os comunistas $\square$ silenciosamente. Em 30 de março de 1964, pouco antes do Golpe, latifundiários seguiram para o bairro Santa Teresa (Governador Valadares), onde estava a sede do sindicato, e abriram fogo sobre os que ali se encontravam $\square$ (BORGES, 2004). Camisasca (2009) descreve alguns detalhes desse acontecimento:

No dia 30 de março, liderados pelos proprietários de terras, grupos armados abriram fogo contra a sede do sindicato rural, que era também a residência de Chicão. $\mathrm{Na}$ troca de tiros entre os camponeses e o grupo comandado pelos proprietários de terras, o genro do coronel Pedro Ferreira, Pascoal Souza Lima, morreu ao ser atingido por uma bala na cabeça. Além disso, se feriram,

\footnotetext{
${ }^{6}$ Fazenda próxima à Valadares, doada pelo governo federal ao governo de Minas Gerais na década de 1940, visando que se tornasse um centro de pesquisa agropecuária. Era, na década de 1960, usada como espaço de empréstimo de maquinário para os fazendeiros da região. Sendo por muitos anos utilizada por fazendeiros e para pesquisa de órgãos governamentais, essa fazenda se tornou novamente objeto de luta na década de 1990, sendo alvo de ocupações mediadas principalmente pelo MST.
} 
mas sem gravidade, o repórter do jornal $O$ Combate, Aguinaldo Alves de Freitas, a esposa de Chicão, Edna Maria, e uma de suas filhas, Elizabete, de apenas 5 anos de idade. Já Chicão nada sofrera, pois havia se escondido debaixo de uma cama na casa do vizinho (CAMISASCA, 2009, p. 164).

As relações entre conflitos como esse e o golpe de 1964 são sugestivas, principalmente pelo papel central que Minas Gerais teve nas articulações conservadoras em torno do Golpe. Dessa forma:

[ $\square$ ] o avanço da organização sindical dos trabalhadores rurais em Minas Gerais serviu de motivação para o amplo apoio prestado pelos proprietários rurais e pelo governador Magalhães Pinto, da UDN, ao movimento militar de 64 (FERREIRA NETO, 1999, p. 202).

Em 1964 existiam 40 STRs, em 36 municípios de Minas Gerais, dos quais apenas três tinham reconhecimento jurídico: os de Poté (Vale do Mucuri), Araçuaí (Vale do Jequitinhonha) e Santana do Deserto (Zona da Mata) (FERREIRA NETO, 1999, p. 204). Os sindicatos estavam distribuídos por quase todas as regiões de Minas Gerais, chamando, porém, atenção a pouca existência de sindicatos no Norte de Minas, no Vale do Jequitinhonha e no pontal do Triângulo Mineiro (Ibid., p. 201).

Depois do golpe de 1964, o MSTR passa por forte retração, com a prisão, perseguição e morte de várias lideranças. Em Minas Gerais, houve grande refluxo das lutas e larga concentração fundiária:

Em todo o País e, particularmente em Minas Gerais, esse processo se deu pela incorporação das áreas do cerrado, no Triângulo Mineiro e nas regiões norte e nordeste do Estado, à estrutura de produção agrícola capitalizada, e pela instalação de grandes projetos agropecuários, de irrigação e de reflorestamento nessas regiões (FERREIRA NETO; DOULA, 2003, p. 6).

O depoimento de João do Mucuri contribuiu significativamente para a compreensão das consequências do golpe militar para a organização sindical no Nordeste Mineiro. Poucos dias depois do golpe, ocorreu uma série de prisões e perseguições que desarticularam grande parte das ações desses sindicalistas.

Ai (com o golpe de 1964) desarticulou, saiu prendendo todo mundo! (...) Aqui na região foi um terrorismo, saiu varrendo! (...) Chegaram lá (em Poté) de manhazinha, 6 horas da manhã, aquele tanto de jipe e rural, um tanto de policial lá na praça da cidade, procurou o delegado de polícia e falou que estava lá para prender os dirigentes do sindicato, que era comunista. A polícia me levou a gente para a praça, falou que ia levar para pegar depoimento, colocou no jipe e vieram embora. E ficou 
uma turma deles lá apanhando os documentos do sindicato (João do Mucuri).

João, entre outros sindicalistas, ficou preso por dois dias, sofrendo maus tratos na prisão. Teve seus direitos políticos e sindicais cassados por 11 anos e foi perseguido por muito tempo. Como contou, um dos primeiros objetivos dos militares era confiscar as cartas sindicais e, assim, colocar os sindicatos na ilegalidade:

Eles procuraram a carta sindical! Procuraram numa salinha lá, com um funcionário do sindicato, e não acharam a carta. Aí sempre na cidade tem aquelas pessoa dedo duro: $\square$ Ah, deve tá na casa noiva de Joaquim ou no hospital, a noiva dele trabalha no hospital $\square$. Chegaram lá... Um dia antes a gente já tava sabendo que eles estavam prendendo mesmo! Ela pegou a carta sindical, levou, colocou dentro de um jornal...E no fundão do hospital tava sendo reconstruído o hospital, tinha uma pilha de tijolos. Ela abriu aquela pilha de tijolos, colocou lá dentro e fechou! Ai eles chegaram e falaram pra ela: $\square$ Nós viemos aqui pegar a carta sindical! $\square$ Ela: $\square$ O que que é isso? $\square$ (risos). Apertaram ela, procuraram debaixo da cama, nos quartos dos doentes. Não achou de jeito nenhum! E a carta sindical permanece ai até hoje (João do Mucuri).

Vários sindicatos da região que tiveram suas cartas sindicais confiscadas não conseguiram voltar a funcionar ou tiveram grande dificuldade para conseguir novamente o documento. Nos anos seguintes, o clima de vigilância sobre os sindicatos dificultou a organização dos trabalhadores rurais. Em Poté, mesmo conseguindo manter a carta, o sindicato permaneceu desarticulado por vários anos:

Sempre, sempre eles vinham em cima para saber como é que o Padre e o Bispo orientavam para fazer as guerrilhas, invasão de terra... E eu: $\square$ Não, não tem nada diss $\square \mathrm{E}$ eles insistiam para a gente declarar que tinha pra eles condenar o padre e o bispo. (...) Foi uma perseguição grande demais! (...). Até o golpe a gente reunia todo primeiro domingo do mês lá em Poté, com uma média de 200 pessoas. Aí, depois do golpe, nós ficamos três meses sem condição de fazer nada. Aí o Padre (Teodoro) sempre incentivando: — Vamos fazer reunião de novo! $\square$ A primeira reunião que nós fizemos, uns três meses depois, teve que pedir autorização para o delegado de polícia. E ai ele mandou alguém da polícia para ficar lá pra ver o que a gente ia fazer. $\mathrm{Na}$ primeira reunião foram 5 pessoas! Nós levamos mais de 2 anos para reunir uns 30 ! (João do Mucuri).

O clima de insegurança frente à vigilância constante afastou grande parte dos trabalhadores rurais do sindicato de Poté e dificultou que esse desenvolvesse abertamente ações em defesa do trabalhador, formas de enfrenta- 
mento e questionamento sobre as relações de poder. João narra um desses momentos de vigilância:

\begin{abstract}
Sempre vinha policial! (...) Um tenente da polícia, fardado. (...) $\mathrm{O}$ prefeito veio com um tenente que veio para conversar com a diretoria do sindicato. Aí eu conversei com o tenente, ele falou: $\checkmark$ To vindo para ver o negócio do Ministério do Trabalho, ver as contas, e tal e tal $\square(. .$.$) Eu cheguei lá e cadê o tenente \triangle A h$, ele foi para o hotel, disse que ia almoçar e depois vem pra cá Quando deu 3 horas na hora do ônibus voltar, eu falei: Eu vou lá ver! Cheguei no hotel e perguntei, eles falaram: Não, o tenente almoçou aqui e saiu $\square$ Aí eu entrei no ônibus e não vi ninguém de farda. Aí alguém falou assim: $\square$ O senhor tá me procurando, né? $\square$ Era ele mesmo! Com um chapéu de couro, uma bota amarela (risos). Foi embora (sem ir no sindicato) (...). Aí depois algumas pessoas falaram comigo que aquele faqueiro saiu lá perguntando: $\square$ Como é que o sindicato aqui funciona? Joga o trabalhador contra o patrão? Eles invade a terra dos outros? Saiu lá perguntando nos barzinho (risos). Foi no hotel, trocou de roupa e foi investigar (risos). Pelas informações ele acabou de concluir que não tinha nada. Desse jeito que eles faziam! Isso 11, 12 anos depois do golpe (João do Mucuri).
\end{abstract}

Apesar de formas de violência como as retratadas anteriormente e de obstáculos para a organização e mobilização sindical ${ }^{7}$, nesse período, várias organizações buscaram resistir. Como salientado acima, a estrutura sindical encontrou grandes entraves nesse período, mas foi espaço importante para denúncias, resistências e fortalecimento das lutas posteriores. A FETAEMG $\square$ entidade sindical filiada à Confederação Nacional dos Trabalhadores na Agricultura (CONTAG) - foi fundada em 1968, com apenas o número mínimo necessário, cinco sindicatos legalmente reconhecidos. No entanto, sua fundação marca uma nova etapa para a organização do MSTR mineiro, constituindo-se como uma representação mais geral dos trabalhadores rurais em Minas Gerais e uma das FETAGs mais expressivas de todo o país $\square$ (FERREIRA NETO, 1999, p. 205).

Após o golpe de 1964, a influência dos Círculos Operários Cristão vai prevalecer sobre o MSTR mineiro e direcionar o perfil de atuação da FETAEMG ${ }^{8}$ no sentido das determinações estatais, o que deixava a reforma agrária como tema marginal e, muitas vezes, proibido. No entanto, outros atores $\square$ de grupos como PCB, AP e Ligas Camponesas $\square$ mesmo enfraquecidos, continuaram influenciando, o que configurou falta de unidade e certo caráter ambíguo na atuação da Federação (Ibid., p. 211).

${ }^{7}$ Apesar de Ferreira Neto e Doula (2003, p. 17), e Sgrecia e Gadelha (1987, p. 52) caracterizarem a atuação sindical no período militar como $\square$ assistencialista $\square$, consideramos a necessidade de buscar pesquisas que descrevam e discutam as atuações sindicais noutros sentidos, para o contexto de Minas Gerais nesse período.

${ }^{8} \mathrm{~A}$ forma de atuação sindical da AP e do PCB, apesar de se dar dentro dos limites impostos pelo Estado, guardava certa dose de $\square$ rebeldia e ruptura $\square$ Já a atuação dos Círculos Operários estava em perfeita sintonia $\square$ com as diretrizes estatais (FERREIRA NETO, 1999, p. 211). 
Nesse período, ela evitava um envolvimento mais explícito com a luta pela reforma agrária. A FETAEMG era a única representante dos trabalhadores rurais reconhecida legalmente e, assim, lutava dentro dos limites do que era permitido pelo Estatuto da Terra, principalmente denunciando arbitrariedades e dando apoio jurídico. Assim, voltou-se principalmente para o atendimento de necessidades individualizadas, em detrimento da formação de demandas e ações coletivas (FERREIRA NETO, 1999, p. 222). Parte desse processo foi retratado por João:

Logo em 70, 71 criou o Fundo de Assistência ao Trabalhador Rural, dentro daquele programa Pro-Rural, que é hoje a Previdência Social. E ai eles colocaram nas mãos dos prefeitos a incumbência de fundar sindicatos. Aqui em Teófilo Otoni mesmo não chegou a ter sindicato antes de 64 , foi só nesse modelo aí. (...) E aí punha dentro do sindicato um ambulatório médico e odontológico, punha uma farmacinha pra dar os remédios. E aí controlava os sindicatos assim. Em vez do sindicato fazer uma luta de reivindicação pela terra, pelos direitos trabalhistas ou mesmo pelos direitos previdenciários, o sindicato ia fazer o trabalho assistencial (João do Mucuri).

Essa perda de autonomia teve como contraponto a criação de uma importante estrutura física, intensa filiação e estabilidade financeira, o que, segundo Ferreira Neto e Doula (2003, p. 9), iria possibilitar ao sindicalismo mineiro se apresentar, após a abertura política nos anos 80 , como o principal mediador da luta pela terra em Minas Gerais $\square$ Assim, o autor salienta também como a federação mineira se destacou das demais nesse contexto:

Apesar dos limites impostos pelo Estado dificultarem a ação política da Federação, esse mesmo processo, a partir da aceitação das regras impostas unilateralmente significava o acesso a enorme receita financeira que iria possibilitar, em pouco tempo, que a FETAEMG consolidasse uma estrutura física e administrativa dificilmente imaginável para uma federação de trabalhadores rurais (FERREIRA NETO, 1999, p. 226).

Em 1975, na região de Poté $\square$ com base nos trabalhos das Comunidades Eclesiais de Base (CEBs) ${ }^{9}$ organizadas pelo padre português Jerônimo Nunes, um dos fundadores da Comissão Pastoral da Terra (CPT) de Minas Gerais $\square$ começam a surgir oposições sindicais críticas em relação a esse modelo. João fez parte desse grupo:

Quando foi em 75 lá em Poté já tinha um padre português, padre Jerônimo fez um trabalho muito bom; ele iniciou com as CEBs

\footnotetext{
${ }^{9}$ As Comunidades Eclesiais de Base geralmente tratavam-se de grupos de reflexão desenvolvidos por setores progressistas da Igreja Católica em quase todo o Brasil, principalmente nas décadas de 1970 e 1980 . Fortemente influenciados pela Teologia da Libertação e pelas diretrizes do Concílio Vaticano II, esses grupos articulavam fé e política, dando base para uma série de mobilizações de organizações e movimentos sociais populares.
} 
e reestruturou o trabalho que padre Teodoro tinha deixado. (...) Reunimos e achamos que tinha que fazer uma chapa de oposição aquela diretoria que estava lá controlada pelo governo. (...) Fomos eleitos por dois mandatos (João do Mucuri).

Essa vitória, para João, significou a retomada dos trabalhos anteriores, voltados para a proteção do trabalhador rural contra o processo de exploração e expulsão da terra. No entanto, devido à forte repressão, evitavam o enfrentamento direto, numa postura de negociação e convencimento frente às autoridades do Regime e fazendeiros da região. Quando questionado sobre qual mudança seu grupo propiciou ao entrar no sindicato em 1975, João do Mucuri retrata algumas ações:

Continuava aquela luta... do que tinha terra tirando os outros, tirando o agregado, tirando o vizinho menor. E nós fizemos um trabalho de...de...de conversar com os donos de terra pra não... Porque daquela maneira não era certo (João do Mucuri).

Esse grupo buscou o cumprimento das leis trabalhistas e a regularização das relações de parceria entre fazendeiros e trabalhadores rurais, introduzindo os contratos de parceria, que traziam algumas garantias para os trabalhadores rurais (meeiros, parceiros, etc.). Também contribuíram na regularização das terras de posseiros, dificultando a sua expulsão. Assim, buscavam a medição das propriedades e marcavam as terras, documentando esses direitos, evitando que os proprietários maiores $\sqsubset$ empurrassem com a barriga do boi $\square$ os posseiros para fora de suas terras.

Nos anos de 1980, em consonância com o processo de redemocratização, a FETAEMG constrói um sindicalismo mais voltado para as lutas dos trabalhadores rurais assalariados, a educação sindical ${ }^{10}$ voltada para essas lutas e o entendimento da greve enquanto recurso legítimo de pressão. Assim, também ocorre um processo de descentralização e aumento da agressividade das lutas sindicais em Minas Gerais (FERREIRA NETO; DOULA, 2003).

\begin{abstract}
A partir do início dos anos 80, associado ao processo de transformação política que estava vivendo o país, tem início um conjunto de transformações tanto nas concepções correntes sobre o significado do movimento sindical, com a busca de alternativas que superassem o caráter assistencialista que predominava na estrutura nacional do MSTR, quanto a construção de novas alternativas de luta pela reforma agrária.(FERREIRA NETO, 1999, p. 147).
\end{abstract}

\footnotetext{
${ }^{10}$ Parte dessa educação era desenvolvida pela FETAEMG em Delegacias e Polos Regionais, que visavam ampliar e legitimar ações junto à base e formar lideranças. Nesse período foram criadas delegacias em Uberaba (Delegacia Regional do Triângulo Mineiro) e em Almenara (Delegacia Regional do Vale do Jequitinhonha) e polos em Governador Valadares, João Pinheiro e Montes Claros (FERREIRA NETO \& DOULA, 2003).
} 
Nesse novo momento, a luta dos assalariados tem proeminência, ficando a reforma agrária ainda apenas como uma bandeira marginal Porém, esse foi o início do afastamento em relação à lógica sindical imposta pelo Estado, mesmo a maior parte dos sindicatos permanecendo na lógica anterior. $\mathrm{O}$ depoimento de João contribuiu também para compreender as dificuldades em se desenvolver ações mais incisivas em relação às disputas pela terra, como apoio as resistências de posseiros, diante da forte repressão que permanecia:

\begin{abstract}
Não tinha apoio (...) e era muito vigiado pela polícia (...) Não era fácil! Era muito perigoso. Na década de 80 teve muitos líderes de sindicato que foram mortos por essa luta (de apoio às lutas de resistência de posseiros) de lutar, resistir. A luta pela terra matou muito dirigente sindical! Aqui em Minas mesmo: Em Unaí, matou seu Júlio Miranda, lá no Triângulo foi Durval, no norte de Minas, Eloy (...) Aqui em Itaobim, seu José Dias (João do Mucuri).
\end{abstract}

No início da década de 1980, a FETAEMG, entre outras organizações em Minas Gerais, manifesta publicamente sua solidariedade em relação às ocupações realizadas pelos Sem Terra do sul do Brasil. Em algumas edições do Jornal Sem Terra ${ }^{11}$ de 1981 apoios desse tipo são mencionados, em notas nos jornais dos dias 09/07 (p. 9) e 11/09 (p.10).

Em 1984 foi realizado em Contagem o I Encontro dos Trabalhadores Sem Terra de Minas Gerais, com forte influência das mobilizações que ocorriam no Sul, marcando uma maior identificação com suas demandas. Na reportagem ficam claras as articulações entre integrantes da Comissão Pastoral da Terra (CPT), de Minas Gerais, e do Movimento dos Trabalhadores Rurais Sem-Terra (MST) do Sul e Rio de Janeiro no Encontro, que também apontou as principais regiões nas quais as mobilizações deveriam ocorrer: Nordeste e Norte de Minas Gerais, regiões de maior exploração e conflitos pela terra.

A Comissão Pastoral da Terra, criada em 1975, em parte seguindo a tradição de atuação progressista de setores da Igreja Católica, foi importante instrumento na promoção de justiça social e direitos humanos no campo (POLETTO, 2010, p. 138). Inserida numa longa trajetória de lutas, essa organização surge ligada pastoralmente à Conferência Nacional dos Bispos do Brasil (CNBB), mas com autonomia organizativa, e teve como algumas de suas principais atuações a defesa da função social da terra $\square$, como fora regulamentada pelo Estatuto da Terra, referência legal que norteava a ação de várias organizações no campo.

A partir de meados da década de 1980 houve maior proeminência de lideranças renovadoras no MSTR, em interação com a ascensão de novos movimentos sociais. A ideia de movimento social aqui empregada está ligada às ações desencadeadas por grupos que se colocam o objetivo de mudar a distribuição de poder, formas de interação e ideais culturais vigentes na sociedade

${ }^{11}$ As edições do Jornal Sem Terra- produzido pelo MST - estão disponíveis no Centro de Documentação e Memória da UNESP (CEDEM) e online no Armazém Memória. 
(ALEXANDER, 1998). Essa ideia também está relacionada com a sistematização e publicização de determinados projetos de sociedade, de determinadas causas, o que, em muitas análises, passa pela delimitação de um ou mais adversários no seio da sociedade e pela formação de redes de mobilização (NEVEU, 2005). No contexto de redemocratização, o MST apresentou-se como um dos movimentos que mais influiu nas transformações na atuação sindical no meio rural.

Nesse processo de inserção de novos movimentos, vários sindicatos de trabalhadores rurais começam a adotar posturas mais incisivas na condução da luta pela terra, principalmente no Noroeste de Minas Gerais, considerando as ocupações de terra como objetivos mais concretos.

Um marco importante ocorreu no município de Varzelândia, no Norte de Minas Gerais, onde posseiros retomaram um antigo conflito ${ }^{12}$ contra grileiros que os expulsaram da Fazenda Cachoeirinha na década de 1960, ocupando novamente o local em 1981. A FETAEMG passou acompanhar o conflito, que se tornou uma questão pública pela inserção na grande mídia estadual. Apesar dessa ação não ser uma "mediação efetiva", Ferreira Neto afirma que:

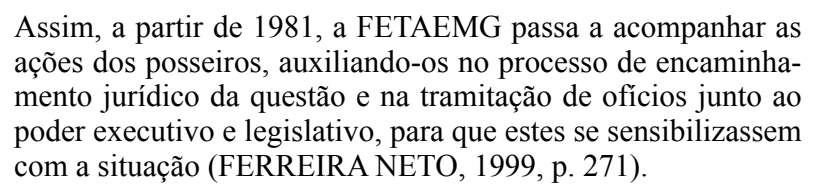

Entendemos as ações de mediação (NEVES, 2008) enquanto busca pela constituição de novos arranjos de significados com base em elementos dos vários universos de significação em relação, inclusive, aos do próprio ator que exerce o papel de mediador, o que possibilita as ações conjuntas dos atores em interação Assim, essas ações dependem de um envolvimento efetivo e proeminente na busca pela definição dos rumos das mobilizações, o que, como foi salientado anteriormente, ainda não podia ser identificado nas ações da Federação em relação aos conflitos em curso.

Apesar das novas iniciativas sindicais, a Federação ainda mantinha uma posição conciliatória e grande dificuldade de romper com a lógica estatal. Assim, "até o final da década de 1980, a luta pela terra e o apoio direto aos trabalhadores rurais estiveram mais presentes no discurso oficial formulado pela Federação do que em suas ações efetivas $\square$ (FERREIRA NETO, 1999, p. 281). Em consonância com essa afirmação, João nos contou que:

A FETAEMG, pra ser sincero, nunca enfrentou muito a luta da terra mesmo não. (...) Eu sou FETAEMG, mas eu acho que a FETAEMG tinha que fazer mais. (...) O problema da terra é

\footnotetext{
${ }^{12}$ Esses posseiros, que ocupavam a área desde a década de 1940, foram expulsos por grileiros apoiados por policiais militares, inicialmente tentaram várias vezes reocupar as terras, sendo novamente expulsos, sofrendo agressões e assassinatos. Em seguida, guardaram solução jurídica por quase vinte anos no vilarejo de Cachoeirinha, voltando a se mobilizar para a reocupação em 1981 (FERREIRA NETO, 1999, p. 269).
} 
muito complicado. Muitas vezes o proprietário prefere gastar mais do que o valor da terra para segurar a terra, para mostrar... questão de honra. Muito complicado, tem dado muita morte em consequência da luta (João do Mucuri).

Em 1985, o Jornal Sem Terra noticia o que considerou ser o início das ocupações em Minas Gerais (Figura 1), não deixando claro quais foram as lideranças dessas mobilizações, porém identificando claramente essas ações com as mobilizações que os sem-terra desenvolviam no sul do Brasil.

Figura 1

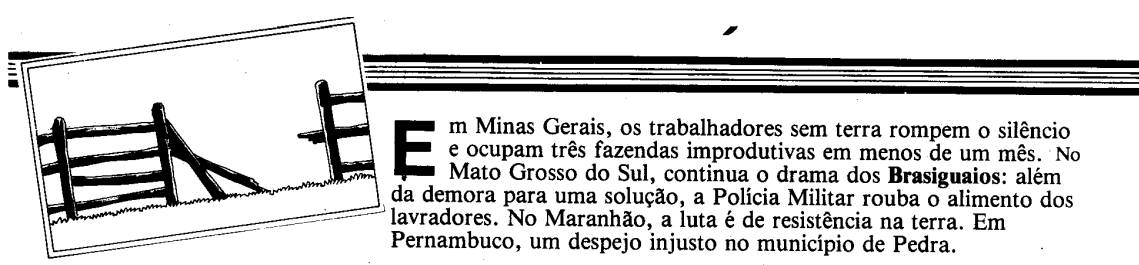

Minas Gerais Começam as ocupações

$\begin{array}{ll}\begin{array}{l}\text { Em Minas Gerais, os trabalhado- } \\ \text { res sem terra também começam a ti- }\end{array} & \begin{array}{r}\text { hectares estão em nome dele. } \\ \text { Cinco dias após a ocupação, um }\end{array} \\ \text { rar a Reforma Agrária do papel. } & \text { delegado de polícia (comandando } \\ \text { Num curto espaço de tempo, reali- } & 20 \text { soldados armados de metralha- } \\ \text { zaram três ocupações em diferentes } & \text { dora e granadas) despejou os sem } \\ \text { pontos do Estado. A primeira foi } & \text { terra, sem ordem judicial. Os lavra- } \\ \text { no dia } 17 \text { de agosto, no municipio } & \text { dores foram jogados nas vilas de } \\ \text { de Iturama (região oeste), quando } & \text { Iturama, mas se reorganizaram e } \\ 70 \text { familias entraram na Fazenda } & \text { acamparam em frente ao sindicato, } \\ \text { Bartíria, abandonada há } 10 \text { anos. A } & \text { onde aguardam a desapropriação } \\ \text { fazenda tem 1.600 hectares e dela se } & \text { da fazenda. Durante a ocupação, } \\ \text { diz dono Gervásio do Amaral Co-- } & \text { dois lavradores foram presos e mal- } \\ \text { mar, morador de Votuporanga, } & \text { tratados pela polícia. Os sem terra } \\ \text { São Paulo. Mas, segundo registro } & \text { tratados } \\ \text { no cartório de Iturama, apenas } 620 & \text { têm o apoio do bispo da região. }\end{array}$

Fonte: Jornal Sem Terra $\square$ n. 47, setembro de 1985, p. 6

Diferentemente da reportagem anterior, aqui são relatadas ações concretas de ocupação, inclusive enfatizando a violência policial decorrente. A contestação da propriedade da terra aparece nos argumentos de que as terras são improdutivas, sem documentação ou abandonadas. Essas ocupações foram acompanhadas regularmente pelo Jornal, principalmente a de Iturama (Triângulo Mineiro). Noutra reportagem, apesar de mencionar a pressão sobre o Sindicato de Matozinhos, é salientada a ausência de coordenação dos trabalhadores nessa ocupação, o que pode indicar que o movimento sindical não assumiu objetivamente a organização dessas ações. Por outro lado, alguns meses depois, o Jornal elogia a organização em Iturama, contrastando-a com a de Matozinhos, o que pode indicar que havia mediação nessas ações.

Segundo Ferreira Neto (1999), somente a partir de 1987, parte do MSTR intensificou o apoio aos trabalhadores rurais nesses conflitos, vendo as ocupações de terra como alternativas legítimas de luta pela terra e, assim, contribuindo efetivamente em sua organização. No entanto, a direção da FETAEMG 
considerava a reforma agrária uma luta marginal, divergências que estavam envoltas em intensas disputas pelo controle da Instituição

Numa nova configuração de forças políticas - marcada pela ascensão da Comissão Pastoral da Terra, do Partido dos Trabalhadores (PT) e da Central Única dos Trabalhadores (CUT) como atores cada vez mais relevantes nas ações de mobilizações dos trabalhadores rurais $\square$ as ações da Federação passaram a ser objeto de frequentes e intensas críticas e tentativas de transformação.

Encontramos reportagem do Jornal Sem Terra sobre essas articulações em Minas Gerais (Figura 2) $\square$ associadas à realização de uma grande assembleia em Poté (Vale do Mucuri) no ano de $1987 \square$ destacando a inserção do MST nessas disputas, movimento que estaria mobilizando os trabalhadores rurais para essa renovação e para sua organização na região.

Figura 2

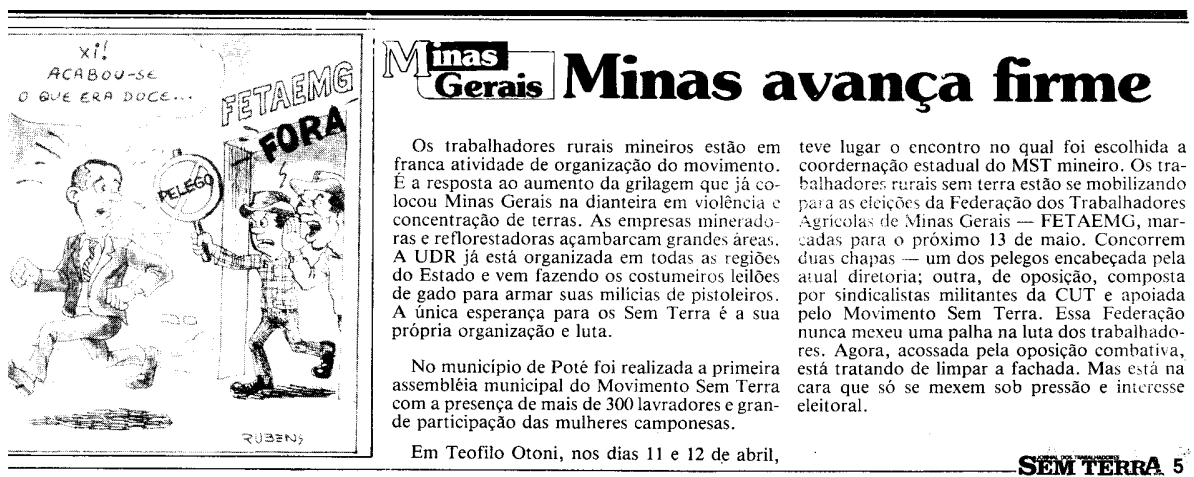

Fonte: Jornal Sem Terra $\square$ n 62, maio de 1987, p. 5

A figura indica claramente a busca pela renovação na FETAEMG, acusando a atual direção de submissão ao governo. A imagem reflete o clima acusatório nessas disputas, assim como a ideia de que a oposição sindical deveria tomar o controle da Federação, expulsando aqueles que eram por eles considerados como alinhados ao poder governamental e elitista. Nessa reportagem, pela primeira vez, é feita menção à organização dos fazendeiros $\square$ no caso, os leilões organizados pela União Democrática Ruralista (UDR) ${ }^{13}$ - como fator que deveria chamar atenção para a necessidade de organização e união dos trabalhadores rurais para o enfrentamento desses adversários.

A busca pela renovação nos quadros da FETAEMG é evidente. CPT, CUT e, mais à distância, o MST estavam mobilizados para a vitória de uma nova chapa nas eleições que, supostamente, mudaria o perfil de atuação da instituição. Apesar de a chapa oposicionista ter sido derrotada, a vitória da situação

${ }^{13}$ A UDR foi uma das principais formas de organização do patronato rural nas décadas de 1980 e 1990, marcada pela violência - em defesa da grande propriedade fundiária - contra trabalhadores rurais mobilizados na luta pela terra e reforma agrária. Assim, esse grupo conferiu certa identidade a grande parte do patronato rural brasileiro, sendo importante meio de organização e representação (BRUNO, 1996). 
foi construída de forma negociada com setores de oposição, principalmente da região nordeste de Minas Gerais, o que significou a incorporação de novas forças na direção da FETAEMG, que assumiram o controle em 1990 (FERREIRA NETO, 1999).

Um dos principais núcleos de oposição à atuação da FETAEMG estava nos sindicatos do Vale do Mucuri. Vinculados principalmente a setores progressistas da Igreja Católica, por meio do trabalho da CPT, esses sindicatos fizeram fortes críticas à direção da Federação. (Ibid.). A situação de marginalidade da reforma agrária nas pautas da FETAEMG mudou, em parte, no início da década de 1990 com a ascensão de um novo conjunto de lideranças, motivado por uma postura mais favorável à luta pela reforma agrária, o que ocasionou, principalmente por iniciativas regionais, a criação de um grande número de assentamentos rurais em Minas Gerais na década de 1990 (Ibid., p. 315).

Assim, os STRs passaram a identificar áreas improdutivas, selecionar e organizar os trabalhadores rurais para as ocupações, ficando a FETAEMG como responsável pelo suporte dessas ações, no respaldo jurídico, informacional e estratégico para as mobilizações regionais. As ocupações de terra do MSTR foram concentradas na região Noroeste do estado, onde existiam lideranças sindicais mais voltadas para a problemática da reforma agrária, o que gerava tensões e disputas na Federação, em parte responsáveis pelas crescentes transformações em seu interior. De forma geral, a direção da FETAEMG alegava que essa era uma luta custosa em face dos crescentes problemas financeiros da Instituição, devendo ficar em segundo plano (FERREIRA NETO, 1999).

No final dos anos de 1980 e início de 1990 foram organizadas importantes ocupações de terra pelos STRs do Noroeste de Minas Gerais, levando à criação de vários assentamentos. A influência de outros atores nessas ações, como MST e CPT, não está muito clara, porém, ao que tudo indica, essas relações envolveram tanto relações de parceria quanto de disputa pela proeminência na organização das ocupações. Ao se referir às principais lideranças sindicais que catalisaram esse processo de luta pela terra no Noroeste mineiro, Ferreira Neto afirma que:

[...] o envolvimento desses dois jovens com a Igreja, com partidos políticos, com a CUT, com o MST e com o próprio movimento sindical, associado às experiências individuais de cada um, fazem parte do processo de construção de um habitus politico em que a defesa da luta pela terra é a principal referência, o que atribui a essas lideranças um espaço distinto do ocupado por outra lideranças relacionadas com as lutas dos trabalhadores rurais (FERREIRA NETO, 1999, p. 376).

Assim, apesar do MSTR buscar atuar de forma autônoma na condução de suas iniciativas pela reforma agrária, a influência de outros grupos é sugestiva, cabendo, no entanto, precisar o teor dessas relações. No que se refere ao Nordeste de Minas Gerais, a atuação da CPT nas lutas pela reforma agrária 
é mencionada em alguns estudos. A CPT atuou frequentemente em parceria com os STRs e deu nova força para as lutas no Nordeste de Minas (RIBEIRO, 1996). Por meio de missas e reuniões, os membros da CPT articulavam fé e política, organizando trabalhadores rurais para o enfrentamento dos conflitos pela terra e sindicalização.

A entrevista com Fernando - integrante da CPT que atuou nessa região como membro da CPT $\square$ contribuiu para a melhor compreensão dessas ações. Desde o final da década de 1970, ele participou em cursos que relacionavam religiosidade, conquista de direitos e mobilização política:

Há mais de 10 anos, em 88 , eu já frequentava a região do Je-
quitinhonha e do Mucuri dando cursos, principalmente de igre-
ja em geral. E dentro desses cursos de igreja a gente também
fazia cursos de criação, de formação de oposições sindicais.
Nós tínhamos módulos de trabalho com Bíblia e a questão da
terra, onde a gente mostrava muito a história do povo hebreu, a
conquista de Canaã, a conquista da terra prometida, a luta e or-
ganização. A gente sempre tinha nesses cursos um modelo que
era interessante, que a gente trabalhou naquela região toda, que
era a questão do povo hebreu... A gente até usava a Expressão,
os Apiros... Os Apiros eram povos nômades, salteadores que
viviam pelo deserto. Daí a origem da palavra hebreu. Aí a gente
dizia que eram os primeiros sem-terra da história (Fernando,
entrevistado em 13 dez. 2011 pelos autores).

Buscando referências na Bíblia que contribuíssem na percepção das injustiças sociais e necessidade de organização dos trabalhadores, esses membros da CPT foram fundamentais para despertar um sentido de organização no Nordeste Mineiro.

\begin{abstract}
A gente sempre identificava a opressão do Egito, com o faraó, toda a estrutura de classe, com a questão da opressão hoje. Mas sempre tinha uma chave de leitura nesses cursos que era o Êxodo 3, quando Deus diz: Eu vi o sofrimento, a opressão do meu povo no Egito, causada pelos seus opressores. Eu desci para libertá-los $\square$ Então a gente sempre dava esse sentido de relacionar a opressão de 3 mil anos atrás com a opressão de hoje. E que Deus estava do lado da libertação, do lado da organização (Fernando).
\end{abstract}

Nesse período, as dioceses de Teófilo Otoni e Araçuaí eram polos de atuação da Igreja Católica progressista, principalmente nos trabalhos de padres missionários portugueses e italianos. Esses grupos, organizados nas CEBs e CPT, fizeram muitas reuniões e publicavam manuais que contribuíram enormemente na organização dos trabalhadores, divulgando seus direitos, questionando as injustiças sociais e má distribuição da terra, iniciando a formação de uma identidade (OLIVEIRA, 1976) de trabalhador rural sem terra na região. 
Fernando narrou outra iniciativa que marca essa atuação, um cadastramento de famílias na região, no início da década de 1980, instrumento de organização que pode ter contribuído nas futuras ocupações de terra:

Em 1982, antes ainda do MST, nós fizemos umas fichas rosa, que era para cadastrar quem queria terra, ocupar terra. Em 1982! Fizemos mais de 100 mil fichas dessa para o pessoal nosso da CPT levar para o interior. Pegava os dados, número de famílias, quantas pessoas têm, se tem terra, qual o tamanho da terra, se não tem... (...) Se a pessoa queria lutar por terra, se queria adquirir terra de outra forma. (...) Agora por que essas famílias da região participaram dessas ocupações? Se alguém fizer um levantamento, vai ver que (as ocupações) têm a ver com esse cadastro que a CPT fez na região. Nós fizemos cadastro em várias dessas cidades: Novo Cruzeiro, Ladaínha, Poté, Itaipé, Itambacuri, Pavão. Porque eram cidades onde tinha trabalho da CPT engajada! (...) Padre Paraíso, Águas formosas, Jampruca. Tudo isso eram regiões que nós demos curso e que a gente trabalhava com a ficha. (Fernando).

Grande parte desses trabalhos se dava em clara oposição ao perfil de atuação da FETAEMG:

Esses cursos, a gente chamava $\square$ cursinhos de base $\square$, eram para preparar a questão da organização, da mobilização das pessoas, na luta dos seus direitos. Aí esses cursos acabavam desencadeando, por exemplo, como conclusões finais, na criação de um sindicato dos trabalhadores rurais onde não tinha, sindicato de linha combativa, linha comprometida com o povo. E caminhava, onde tinha sindicato, pra formação de oposição sindical. Nessa época a gente tinha enfrentamento muito grande com a FETAEMG, porque ela era muito pelega. Depois ela evoluiu bastante; hoje já tem um perfil diferenciado, mas ainda que choca com algum setor do movimento, por causa da forma na condução da luta (Fernando).

Com o passar dos anos, CPT e MST passaram a contar com a parceria da FETAEMG, que, como salientado, transformou suas práticas na condução dos conflitos em convergência com a legitimação das ações de ocupação de terra (FERREIRA NETO; DOULA, 2003). Em meados da década de $1980^{14}$ - em reuniões esporádicas em sindicatos, igrejas e encontros como os da Romaria da Terra $^{15}$ - lideranças do MST que atuavam no sul do País intensificaram

${ }^{14}$ Fernandes (2010) divide a trajetória do MST em gestação (1979-1984), consolidação (1985-1989), institucionalização (1990 até o presente) e mundialização (1996 até o presente). No período da consolidação o MST amplia suas ações para todas as regiões do País e forma sua estrutura organizativa, e no da institucionalização, o MST se torna o principal interlocutor do governo federal a respeito da reforma agrária e é reconhecido internacionalmente (FERNANDES, 2010).

${ }^{15}$ Romarias da Terra são encontros organizados pela Comissão Pastoral da Terra por todo o Brasil. Em Minas Gerais, o evento foi organizado a partir de 1979 e se tornou espaço de discussão e articulação de ações pela Reforma Agrária. 
seus contatos com integrantes de sindicatos, líderes comunitários e membros progressistas da Igreja Católica em Minas Gerais, visando, com base em suas experiências anteriores, desenvolver processos massivos de ocupação de terras nas regiões leste e nordeste do Estado (MOREIRA, 2008).

Encontramos uma menção no Jornal Sem Terra à organização do MST em Minas Gerais, numa pequena nota da sessão $\square$ Vida do Movimento $\square$, na edição de abril de 1986. Apesar de ser a primeira menção encontrada, o uso do termo $\square$ mais uma reunião do Movimento $\square$ indicou que esse não foi o primeiro momento de articulação. Essa suposição é confirmada em vários depoimentos, que relatam reuniões desde 1985 na região.

A disputa pela renovação sindical no final da década de 1980, que discutimos anteriormente, foi retratada no Jornal Sem Terra no que se refere às eleições sindicais de janeiro de 1988, na cidade de Poté, centro das articulações iniciais do MST para ocupações em Minas Gerais. Sobre esse momento de efervescência política, Fernandes (1999) afirma que:

\begin{abstract}
No início do primeiro semestre de 1987 , foi realizada uma assembleia municipal do MST, em Poté, com a participação de aproximadamente trezentos trabalhadores. Em abril, organizaram um encontro regional em Teófilo Otoni, onde deliberam pela ocupação de terra para fazerem avançar a luta. Também decidiram se mobilizar para as eleições da Federação dos Trabalhadores na Agricultura do Estado de Minas Gerais, apoiando a chapa articulada pela Central Única dos Trabalhadores (FERNANDES, 1999, p.126).
\end{abstract}

A tensão, marcada pelas denúncias de repressão e irregularidades, deu o tom dessas eleições. O MST chegou à região envolto em intensas disputas sindicais. A chapa 1, da situação, saiu vitoriosa. Cerca de dois meses depois, Paulo, um dos membros da chapa 2, foi uma das principais lideranças do MST nas primeiras ocupações de terra mediadas pelo MST em Minas Gerais. Apesar desse enfrentamento inicial, ele afirma que esses conflitos foram superados:

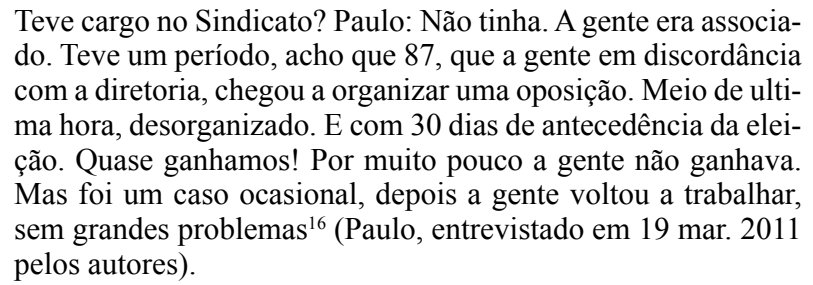

Em fevereiro de 1988 foi realizada a primeira ocupação de terra com proeminência do MST em Minas Gerais, na cidade de Novo Cruzeiro (Vale do Jequitinhonha), com a participação de cerca de 400 famílias da região. Essa

${ }^{16}$ Paulo foi uma das principais lideranças nesse processo e pertencente ao primeiro grupo de militantes do MST formado em Minas Gerais. 
mobilização deu origem ao Assentamento Aruega e impulsionou uma série de movimentações que transformaram o cenário de luta pela terra na região (ZANGELMI, 20007), tendo a forma acampamento (SIGAUD, 2000) como um de seus principais eixos de mobilização e interlocução com o poder público.

A ocupação de Aruega que, como descrito anteriormente, se deu com base em certas mobilizações que já vinham ocorrendo, mas também em oposição a outras práticas e concepções organizativas que não priorizavam a luta pela terra, deu forte impulso para a generalização das ocupações massivas de terra em Minas Gerais, processo que se consolidou inicialmente no Nordeste de Minas Gerais (ZANGELMI, 2007).

\section{Considerações finais}

O processo de intensificação das relações capitalistas no meio rural e expropriação da terra nos anos de 1940 e 1950, aliado à crescente atuação de militantes de movimentos, organizações e partidos políticos na organização de trabalhadores rurais, deu impulso fundamental para a sindicalização em Minas Gerais.

Parte significativa dessas lutas se concentrou no Nordeste Mineiro, região que constituiu uma longa tradição de mobilização e enfrentamento, com forte atuação de movimentos sindicais, setores progressistas da Igreja Católica e, mais recentemente, de militantes do MST, entre vários outros atores.

Esses processos, como salientado anteriormente, estiveram envoltos em tensões e disputas pelo direcionamento das ações, constituindo-se um quadro complexo no qual diversas forças estiveram presentes e influíram, muitas vezes em sentidos distintos, em vários contextos, cujos contornos buscamos descrever nesse artigo.

Durante o regime militar, houve grande repressão, dispersão e enfraquecimento das lutas, sendo pouco conhecidas as formas de mobilização remanescentes, tanto pelas mudanças drásticas nas estratégias de resistência, de caráter mais indireto nesse período, quanto pela dificuldade em dispor de depoimentos de atores que passaram por situações traumáticas de perseguição, cujo receio em explicitar suas lutas secretas muitas vezes perdura até hoje.

No período de redemocratização política do Brasil, essas lutas afloram e se intensificam, alimentando-se do surgimento de novos atores e estratégias, havendo a crescente renovação sindical e legitimação das ocupações de terra enquanto mecanismos de interlocução com o Estado.

Diante dessas reflexões, é sugestiva a ideia de que os processos de mobilização de luta pela terra em Minas Gerais estejam relacionados a experiências de enfrentamento $\square$ por meio de memórias e tradições rearticuladas ao longo do tempo $\square$ em alguns dos diversos contextos de mobilização analisados.

Desse ponto de vista, pode ficar mais inteligível como numa mesma região, o Nordeste Mineiro, tenham ocorrido algumas das principais mobilizações do 
estado, com forte participação desde o movimento sindical inicial, passando pela ação contínua de setores progressistas da Igreja Católica, até essa região se configurar como porta de entrada para as ocupações de terra massivas do MST. Assim, supomos que essa aparente coincidência revela a continuidade de processos de luta que, ao longo do tempo, foram sendo rearticulados de acordo com as experiências anteriores, e que confluíram para o amadurecimento de certas concepções e práticas voltadas para o enfrentamento político e social, para as quais as ocupações de terra adquiriram caráter emblemático.

Os resultados da pesquisa aqui apresentada lançam alguma luz sobre as mobilizações de luta pela terra em Minas Gerais, um processo sobre o qual pouco tem se pesquisado e refletido. De tal modo, as análises realizadas contribuem para que se conheça melhor as raízes de algumas das mobilizações mais recentes e seus significados políticos, num processo mais amplo de mobilizações. Dessa forma, a generalização das ocupações de terra enquanto principais mecanismos de demanda por terra nas décadas de 1980 e 1990 podem ser melhor situadas em face do olhar sobre o processo histórico que as tornaram possíveis.

\section{Referências}

ALEXANDER, Jeffrey C. Ação coletiva, cultura e sociedade civil: secularização, atualização, inversão, revisão e deslocamento do modelo clássico dos movimentos sociais. Revista Brasileira de Ciências Sociais, São Paulo, v. 13, n. 37, p. 5-31, jun. 1998.

BORGES, Maria Eliza Linhares. Representação do Universo Rural e luta pela Reforma Agrária no Leste de Minas Gerais. Revista Brasileira de História, São Paulo, v. 24, n. 47, p. 303-326, 2004.

BRUNO, Regina. Revisitando a UDR: ação política, ideologia e representação. Revista Instituto Estudos Brasileiros. São Paulo, 40, 1996.

CAMISASCA, Marina Mesquita. Camponeses mineiros em cena: mobilização, disputas e confrontos (1961-1964). Belo Horizonte, 201 fls. Dissertação (Mestrado em História) Faculdade de Filosofia e Ciências Humanas da Universidade Federal de Minas Gerais, Belo Horizonte, 2009.

FERNANDES, Bernardo Mançano. Formação e territorialização do MST no Brasil. In: CARTER, Miguel (Org.). Combatendo a Desigualdade Social: o MST e a Reforma Agrária no Brasil. São Paulo: Ed UNESP, 2010.

FERREIRA NETO, José Ambrósio. Lideranças Sindicais e Ação Coletiva: A FETAEMG e a luta pela terra em Minas Gerais. Rio de Janeiro, 413 fls. Tese (Doutorado em Desenvolvimento, Agricultura e Sociedade). Centro de Pesquisa em Desenvolvimento Agricultura e Sociedade/ Universidade Federal Rural do Rio de Janeiro, Rio de Janeiro, 1999.

FERREIRA NETO, José Ambrósio; DOULA, Sheila Maria. Assentamentos Rurais: Organização, Mobilização e Imaginário Social. Visconde do Rio Branco: Suprema, 2003.

MARTINS, José de Souza. Os camponeses e a politica do Brasil. São Paulo: Editora Vozes.1981 
MOREIRA, Crispim. Vida e luta camponesa no território: casos onde o campesinato luta, marcha e transforma o território capitalista. Belo Horizonte, 252 fls. Tese (Doutorado em Geografia) UFMG/Departamento de Geografia, Belo Horizonte, 2008.

NEVES, Delma Pessanha. (Org.). Desenvolvimento social e mediadores politicos. Porto Alegre: Ed. UFRGS, 2008.

NEVEU, Érik. Sociologie dês mouvementssociaux. Paris: Le Découverte, 2005.

OLIVEIRA, Roberto Cardoso de. Identidade, etnia e estrutura social. São Paulo: Livraria Pioneira, 1976.

ONDETTI, Gabriel; WAMBERGUE, Emmanuel.; AFONSO, José Batista Gonçalves. De posseiros a sem-terra: o impacto da luta pela terra do MST no Pará. In: CARTER, Miguel. Combatendo a desigualdade Social: o MST e a Reforma Agrária no Brasil. São Paulo: Ed. UNESP, 2010 .

PEREIRA, Carlos Olavo da Cunha. Nas terras do rio sem dono. Rio de Janeiro: Codecri/Pasquim, 1980.

POLETTO, Ivo. A Igreja, a CPT e a Mobilização pela Reforma Agrária. In: CARTER, Miguel (Org.). Combatendo a Desigualdade Social: o MST e a Reforma Agrária no Brasil. São Paulo: Ed UNESP, 2010.

RIBEIRO, Eduardo Magalhães (Org). Lembranças da terra: histórias do Mucuri e Jequitinhonha. Contagem: CEDEFS, 1996.

ROSA, Marcelo. A forma movimento $\square$ como modelo contemporâneo de ação coletiva rural no Brasil. In: FERNANDES, Bernardo Mançano; MEDEIROS, Leonilde Servolo. de; PAULILO, M. I. (Orgs). Lutas Camponesas Contemporâneas: condições, dilemas e conquistas. São Paulo: Ed. UNESP, 2009. (Vol. II).

SGRECIA, Alex.; GADELHA, Edmar. Movimento rural: 1970-85. In: POMPERMAYER, Malori José. (org.), Movimentos sociais em Minas Gerais: emergências e perspectivas, Belo Horizonte: Ed. UFMG, 1987

SIGAUD, Lygia Maria. Forma Acampamento: Notas a Partir da Versão Pernambucana. Novos Estudos Cebrap, [S.1], v. n. 58. p.73-92, nov., 2000.

ZANGELMI, Arnaldo José. História, Identidade e Memória no Assentamento Aruega $\square$ Novo Cruzeiro/MG. Viçosa, 156 fls. Dissertação (Mestrado em Extensão Rural). Departamento de Economia Rural, Universidade Federal de Viçosa, Viçosa, 2007.

Submissão em: 26/09/2013

Revisão em: 07/12/2013

Aceite em: 02/02/2014

Arnaldo José Zangelmi é Professor da área de Ciências Sociais na Universidade do Estado de Minas Gerais. Doutor em Ciências Sociais - Desenvolvimento, 
Agricultura e Sociedade da Universidade Federal Rural do Rio de Janeiro Endereço para correspondência: Rua Abelardo Nunes de Moraes, 42. Bairro Maria G. Franca (Cohab Velha). Leopoldina- MG, Brasil. CEP 36700-000.

Fabrício Roberto Costa Oliveira é Professor do Departamento de Ciências Sociais da Universidade Federal de Viçosa (UFV). Doutor em Ciências Sociais em Desenvolvimento, Agricultura e Sociedade, da Universidade Federal Rural do Rio de Janeiro (UFRRJ)

E-mail: frcoliveira@yahoo.com.br

Izabella Fátima Oliveira de Sales é Professora no Centro Federal de Educação Tecnológica de Minas Gerais e doutoranda no Programa de Pós-Graduação em História da Universidade Federal de Juiz de Fora (UFJF). E-mail: izabellaieps@yahoo.com.br 